\title{
Definition of ecological flows downstream of dams located in the South of Portugal: a new method
}

\author{
M. M. Portela \\ Department of Civil Engineering and Architecture, \\ Environment and Water Resources Division, IST, \\ Technical University of Lisbon, Portugal
}

\begin{abstract}
One of the environmental issues related with the numerous dams of the Alqueva irrigation system (South of Portugal) was, and still is, the definition of the ecological regimes. Besides other features, those regimes must account for the extreme water scarcity that characterizes the region.

For the 12 dams of the Alqueva system (either existing or new ones) several methods aimed at defining the ecological flows were applied. The comparison of the ecological flows thus predicted revealed the inadequacy of the different methods, suggesting the need for a new approach capable of providing comparable ecological flows under similar hydrologic constraints. In the previous scope a new method supported by hydrologic and hydraulic criteria was developed. The hydrologic criteria account for the water scarcity and for the temporal irregularity of the natural hydrologic regime and the hydraulic criteria, for the geometry of the cross sections and of the river reaches. The method is briefly described and the ecological flows achieved for 12 case studies are presented.
\end{abstract}

Keywords: ecological flows, hydrologic-hydraulic method, hydrologic regime, hydraulic characteristics, cross section, mean flow velocity.

\section{Introduction: scope of the study}

In the next few years an intense agricultural development is expected in Alentejo (South of Portugal) as result of the construction of the Alqueva dam, located in the Guadiana River and providing a huge reservoir, in fact, the largest artificial 
lake in Europe, with a gross and a net storage capacity of 4500 and 3150 million cubic meters, respectively. Alqueva is the "heart" of an irrigation system that will supply water to 115 thousand hectares, by means of 15 dams spread over the region (existing and new ones), more than $300 \mathrm{~km}$ of open channels and more than $2000 \mathrm{~km}$ of buried conduits [3].

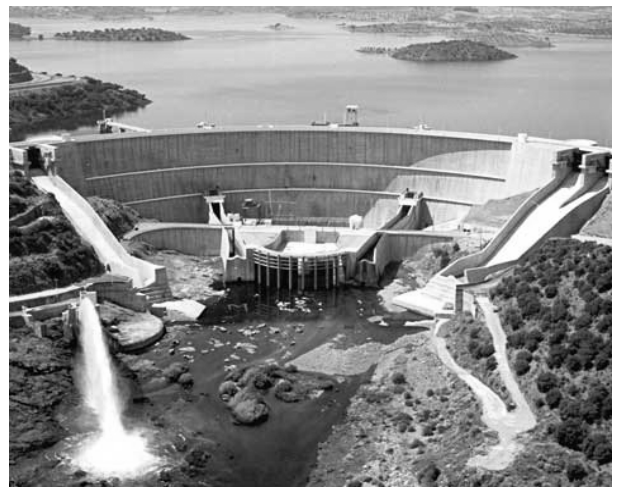

Figure 1: Alqueva dam: view from downstream to upstream.

One of the environmental issues related with the Alqueva irrigation system was, and still is, the definition of the ecological flows to be implemented downstream of each dam. In fact, Alentejo has very specific hydrological constraints being one of the driest of even the driest region of Portugal [11], with a mean annual rainfall of about $500 \mathrm{~mm}$ and a mean annual flow below $150 \mathrm{~mm}$, these hydrological variables also being characterized by a very pronounced temporal irregularity (within each year and among years): about 75 to $80 \%$ of the rainfall and 90 to $95 \%$ of the runoff occur during the wet season (from October to March). Most of the rivers are of the torrential type, only having runoff during a few days of the wet season.

The availability of water that became possible through the Alqueva system may suggest that more water could be launched into the rivers during the dry season, by means of artificial ecological flows. This perspective, though somehow tempting, may not be the most correct one as the local river ecosystems are naturally adapted to extreme water scarcity. Also a wise and tight management of the water in Alentejo is crucial, as the price of that essential asset is not expected to be small.

In the previous scope several methods were tested and compared, aimed at defining the ecological flows downstream of the 12 dams (either existing or new ones) of the Alqueva system.

In a broad sense, the ecological flow for a given river reach is the flow that ensures the conservation and maintenance of the natural aquatic ecosystems, including their biodiversity, the production of species with sporting or commercial interests, as well as the conservation and the maintenance of the riparian ecosystems, of the esthetic features of the landscape or of other features of scientific and cultural interest [2]. An ecological flow regime is a temporal 
sequence of flows, generally defined in a monthly basis. Therefore, any flow or sequence of flows able to preserve the "dynamics" (performance, composition and structure) of the "fluvial-related" ecosystems in natural conditions can be considered an ecological one. This implies that for each river reach there is no such thing as "the ecological flow" but instead a range of ecological flows, varying from minimum ones to maximum ones. With water being a resource that is becoming progressively scarcer, the minimum ecological flows are generally the envisaged ones. It should also be pointed out that nowadays "natural conditions" do not mean pristine or untouchable conditions, which no longer exist, at least in the European rivers. They refer to the conditions that occurred prior to the construction of the infrastructure (such as a dam) that is responsible for changes in the fluvial corridor and, consequently, in the ecosystems connected with that corridor.

The physical organization of each natural fluvial corridor as well as the biologic "performance" of the ecosystems connected with it are deeply dependent on the flow regime as this regime determines the morphologic, the hydraulic, and by extension, the biologic parameters of such a corridor. Consequently, several methodologies and criteria aimed at defining ecological flows utilize the characteristics of the natural river flows, with emphasis on the values of the flows themselves as well as on their temporal variability (within each year and among years). Also, the river flows are most of the time the only easily available data when the definition of a given ecological flow regime is envisaged.

In the previous understanding, three methods of the hydrologic type were applied to 12 dams of the Alqueva system and the ecological flows thus achieved were compared. The methods under consideration were the wet perimeter method [1], a method specifically conceived for Portugal, focusing on the characteristics of the monthly flow series [3], and the basic flow method developed by Palau and Alcázar [5,6]. These methods will be further referred to as the WP method, the INAG method and the QB method, respectively. Their application to each location/dam requires only monthly flow series (INAG and QB methods) or cross sections of the river reach downstream from the dam (WP method).

However, the comparison of the ecological flows thus predicted for the 12 dams showed that: i) at each location the different methods led to disparate ecological flows, as they could be either very large or very small; b) the ecological flows estimated by applying the same methodology to the different cross sections were also quite dissimilar and totally uncorrelated.

This sort of "anachronism" among ecological flows seemed even more abnormal as the region under consideration presents a very "coherent" hydrologic regime, characterized, as previously mentioned, by a very small mean annual flow depth, with almost the same value in the whole region, and by a very pronounced temporal irregularity. Notwithstanding the differences among locations related with the geometry of the cross sections and with the area of the respective watersheds, it was expected to achieve ecological flows of the same order of magnitude when expressed as a percentage of the modulus, $Q_{\text {mod }}$. 
Besides the values of the ecological flows, some hydraulic features of the flow regimes were also compared, namely the flow heights and the mean flow velocities (to simplify the presentation, the mean flow velocity in a given cross section will be referred as the flow velocity). This comparison showed that pronounced differences among ecological flows did not necessarily mean differences equally pronounced among the previous hydraulic parameters. In fact, the flow heights and especially the flow velocities were much closer than the differences among ecological flows could indicate. These results suggested that to recommend an ecological regime based only on the values of the natural flows may not be the most correct decision as only part of the features of the flow regime are taken into account.

In the previous scope, research was carried out in order to develop a method capable of providing comparable ecological flows under similar hydrologic constraints. The method thus achieved is supported by hydrologic and hydraulic criteria $[7,10]$. The hydrologic criteria account for the water scarcity and for the temporal irregularity (within each year and among years) of the natural hydrologic regime and the hydraulic criteria, for the geometry of the cross sections and of the river reaches.

\section{The hydrologic-hydraulic method: general description}

In each cross section and besides its detailed geometry, the application of the hydrologic-hydraulic method (HH method) requires a long series of mean daily flows which, for Portugal, does not represent an obstacle as that kind of series can be easily established by applying the procedures developed in $[8,9]$ and widely proved.

By considering only part of the mean daily flows (in accordance with the criteria shortly presented), the flow heights and the flow velocities are computed, as well as the mean values of those hydraulic parameters. The mean monthly ecological flow is such that its velocity is equal to the mean velocity previously achieved $[7,10]$. Based on that flow, a month-by-month regime is established by applying a kind of "monthly rotation", in accordance with the following equation, which accounts for the temporal variability of the flow regime throughout the year:

$$
Q_{i}=Q_{e c o} \times Q_{a v e_{i}} / Q_{\text {mod }}
$$

In the previous equation $Q_{e c o}$ is the mean monthly ecological flow; $Q_{i}$ the ecological flow in month i; $Q_{a v e}$ the average of the mean daily flows in month $\mathrm{i}$; and $Q_{m o d}$ the modulus (all variables expressed in the same units, usually $\mathrm{m}^{3} / \mathrm{s}$ ). The selection of the range of mean daily flows that supports the computation of $Q_{\text {eco }}$ takes into account the particular hydrologic features of the hydrologic regime in the region in what concerns the extreme flows.

In fact, most of the time the rivers present extremely small flows and often, for two months or even more, no flows at all. Under these constraints the floods, though rare and restricted to a few days per year, may contribute significantly for 
the total runoff, as they may present flood discharge exceptionally large, with maximum values often several set of tens bigger than the modulus. As those floods do not really represent the flow regime in terms of water availability along the year, it was decided to discard part of the maximum mean daily flows, namely those flows with a mean annual duration (for a given set of $n$ years, the duration, D, of a given flow/discharge, $\mathrm{Q}$, is the number of days with flows equal or larger than that one. The mean annual duration, $\overline{\mathrm{D}}$, is the average number of days per year with flows equal or larger than $\mathrm{Q}(\overline{\mathrm{D}}=\mathrm{D} / \mathrm{n}))$ smaller than 5 days (criterion for the extreme large flows).

On the other hand, the irregularity of the hydrologic regime combined with the extremely dry conditions that may occur during a significant part of the year, could justify ecological flows very small as those issues suggest that the local ecosystems are adapted to water scarcity. To prevent, somehow, ecological flows essentially influenced by the water scarcity, part of the flows during the dry season were discarded, namely the flows with mean annual durations $\bar{D}$ (days) computed by the following equation (criterion for the extreme small flows):

$$
D^{\prime} \geq 365-(100-\bar{D})
$$

where $\bar{D}$ (days) is the mean annual duration of the modulus estimated as a function of the mean annual flow depth $\bar{H}(\mathrm{~mm})$ by applying the following equation:

$$
\bar{D}=0.2108 \bar{H}+15.101
$$

The latter equation is supported by the extensive hydrologic regionalization studies developed in $[8,9]$. Those studies proved that the mean annual flow depth is a regional parameter capable of "describing" the hydrologic regime and of providing a powerful tool that enables the establishment of flows series at ungauged river sections. Some of the results from those studies are presented in Figure 2 which contains the representation of the relationship then established between the mean annual flow depth, $\bar{H}$, and the mean annual duration of the modulus, $\bar{D}$.

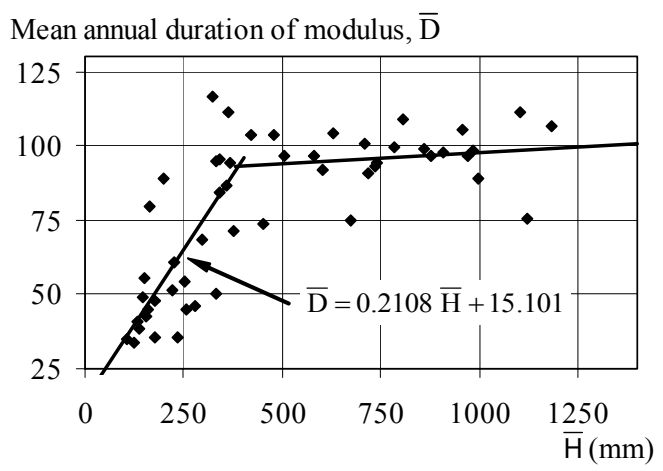

Figure 2: The relationship between $\bar{H}$ and $\bar{D}$, based on the records at 52 Portuguese stream gauging stations. 
Figure 2 shows that for flow depths smaller than $400 \mathrm{~mm}$ a linear dependency between $\bar{H}$ e $\bar{D}$ is expected. The decrease of $\bar{D}$ as $\bar{H}$ decreases denotes a flow regime progressively more irregular, with only a few days with flows greater than $\bar{H}$. For larger values of $\bar{H}, \bar{D}$ becomes more or less constant (approximately equal to 100 days), i.e., independent of $\bar{H}$, which means that the temporal irregularity of the flow regimes is, in relative terms, more or less the same. This kind of "hydrologic behavior" can also be detected in the mean annual flow duration curves, as exemplified in Figure 3, based on the daily records at seven Portuguese stream gauging stations.
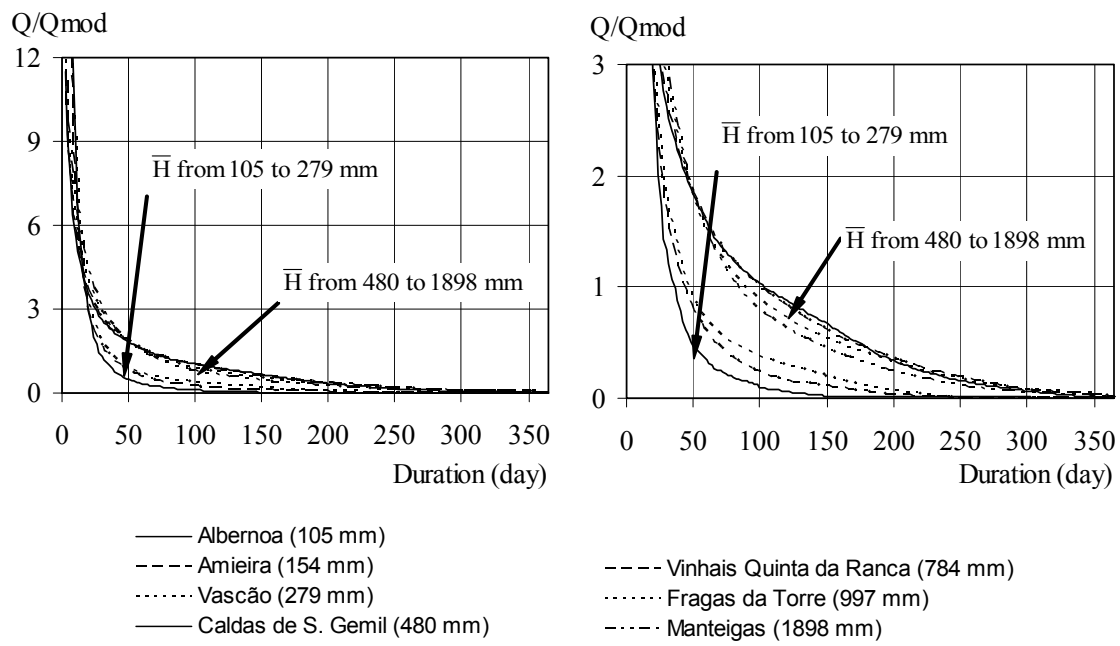

Figure 3: The mean annual flow duration curves at seven Portuguese stream gauging stations (curves and detail of the curves).

The previous results show that in order to increase the ecological flows more days with zero or almost zero flows must be discarded as $\bar{H}$ decreases. To fulfill this criterion eqn. (2) was adopted.

According to the criteria established for extreme large and extreme small flows the average of the velocities (which defines the velocity of the mean monthly ecological flow) was computed based on the daily flows with a mean annual duration comprehended between 5 and $D^{\prime} \geq 365-(100-\bar{D})$ days.

The application of the hydrologic-hydraulic method is schematically represented in Figure 4.

\section{Results}

Table 1 presents some features of the 12 case studies (watershed areas, mean annual flow depths and modulus) along with the ranges of mean monthly ecological flows (expressed in a non-dimensional form, as percentage of the modulus, $Q_{m o d}$ ) provided by the hydrologic-hydraulic method (HH method). 


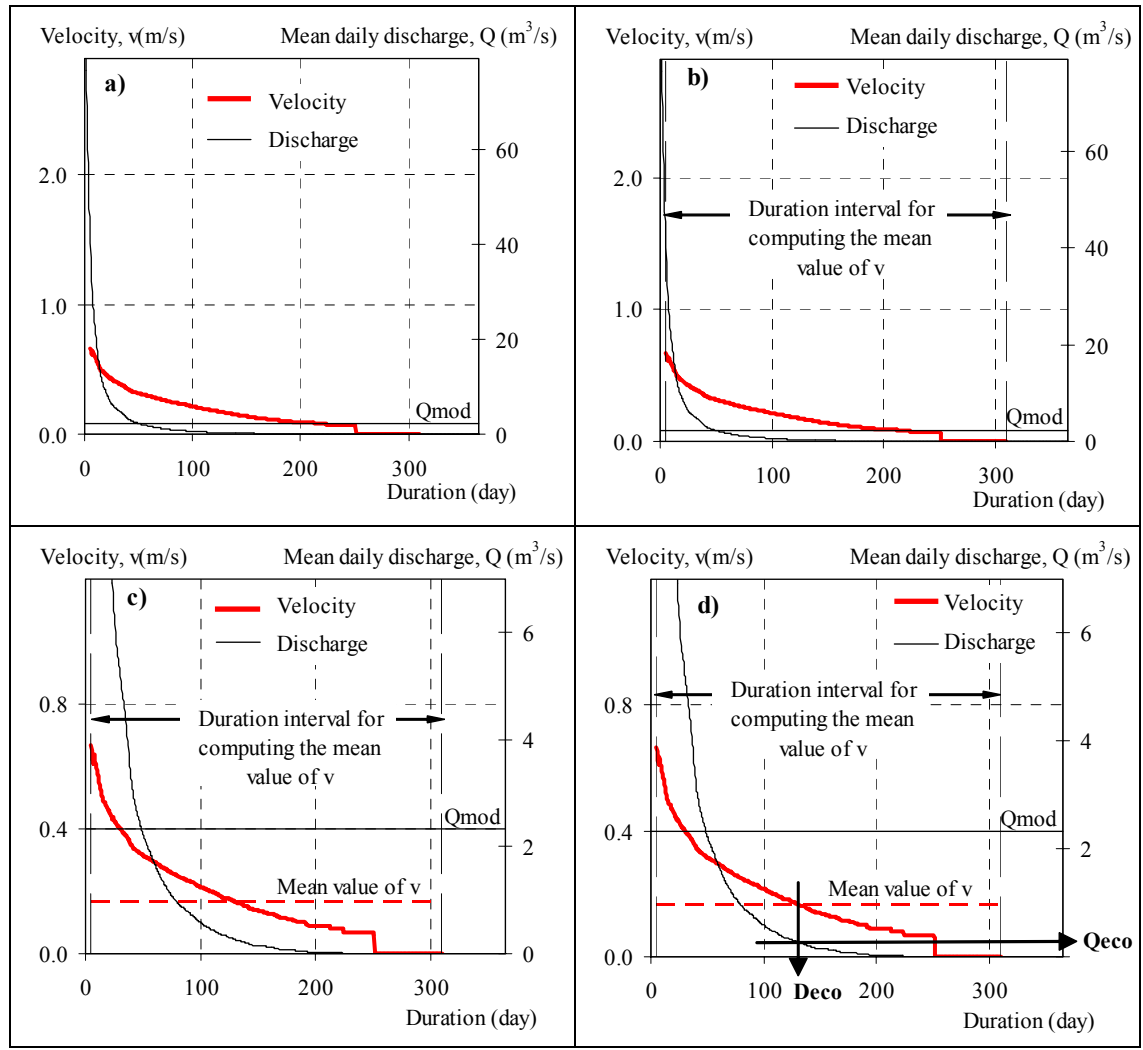
a) Flow velocities ordered by in accordance with the classified mean daily flows.
b) Interval - expressed in durations - considered in the computation of the mean value of the flow velocities.
c) Mean value of the flow velocities.
d) Ecological flow, Qeco, and respective mean annual duration, Deco.

Figure 4: Schematic representation of the application of the hydrologichydraulic method.

As more than one section was analyzed for each case, a range of mean monthly ecological flows is presented instead of a specific value of that flow. To allow a brief comparison among methods, the range of mean monthly ecological flows computed by the wet perimeter method was also include (WP method). The mean monthly ecological flows given by the INAG and the basic flow methods are not presented in Table 1 as the former method always resulted in ecological flows too high (for most of the cases of about $24 \%$ of $Q_{\text {mod }}$ ) while latter method proved not to be applicable in the region as it resulted in ecological flows smaller than $1 \%$ of $Q_{\text {mod }}$. Figure 5 completes Table 1 , by representing schematically the ecological flows of that table (within the range considered for the vertical axis), as well as those from the INAG method. In the figure, the two 
Table 1: Wet perimeter (WP) and hydrologic-hydraulic (HH) methods. Ranges of mean monthly ecological flows.

\begin{tabular}{|c|c|c|c|c|c|}
\hline \multirow{2}{*}{ Dam } & \multirow{2}{*}{$\begin{array}{c}\begin{array}{c}\text { Watershed } \\
\text { area } \\
\left(\mathrm{km}^{2}\right)\end{array} \\
\end{array}$} & \multirow{2}{*}{$\begin{array}{l}\text { Mean annual } \\
\text { flow depth } \\
(\mathrm{mm})\end{array}$} & \multirow[b]{2}{*}{$\begin{array}{c}\text { Modulus } \\
\left(\mathrm{m}^{3} / \mathrm{s}\right)\end{array}$} & \multicolumn{2}{|c|}{ Mean monthly ecological flow } \\
\hline & & & & $\begin{array}{l}\text { WP method } \\
\left(\% \text { of } Q_{\bmod }\right)\end{array}$ & $\begin{array}{l}\text { HH method } \\
\left(\% \text { of } Q_{\bmod }\right)\end{array}$ \\
\hline 1 & 13.1 & 83.7 & 0.035 & 3 to 30 & 11 to 13 \\
\hline 2 & 101.8 & 90.7 & 0.293 & 8 to 13 & 6 to 15 \\
\hline 3 & 6.3 & 94.5 & 0.019 & 8 to 150 & 12 to 14 \\
\hline 4 & 176.2 & 95.5 & 0.534 & 2 to 10 & 10 to 13 \\
\hline 5 & 37.6 & 95.7 & 0.114 & 53 to 285 & 10 to 12 \\
\hline 6 & 351.0 & 124.2 & 1.395 & 1 to 21 & 9 to 11 \\
\hline 7 & 509.0 & 143.8 & 2.321 & 0.4 to 4 & 7 a 12 \\
\hline 8 & 38.9 & 152.0 & 0.188 & 2 to 56 & 11 to 12 \\
\hline 9 & 15.4 & 153.0 & 0.076 & 5 to 37 & 11 to 16 \\
\hline 10 & 48.0 & 155.3 & 0.237 & 4 to 7 & 7 to 9 \\
\hline 11 & 212.0 & 161.0 & 1.081 & 6 to 12 & 7 to 11 \\
\hline 12 & 218.0 & 178.4 & 2.432 & 2 to 3 & 4 to 5 \\
\hline
\end{tabular}

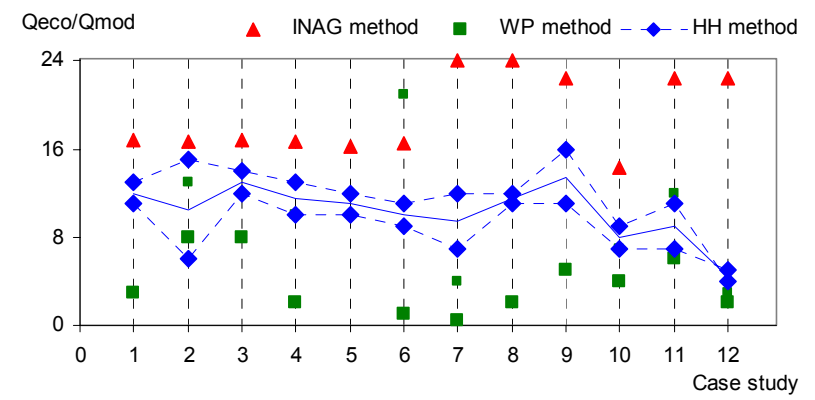

Figure 5: INAG, wet perimeter (WP) and hydrologic-hydraulic (HH) methods. Ranges of mean monthly ecological flows.

dashed lines links the maximum and the minimum ecological flows provided by the $\mathrm{HH}$ method while the full line represents the averages of those values for the 12 case studies.

Table 1 and Figure 5 clearly show that:

i) Despite the differences among watershed areas and among mean annual flows depths and excepting, in a certain way, case 2, the hydrologic-hydraulic method applied to each section always resulted in a narrow range of non-dimensional mean monthly ecological flows in clear opposition to the wet perimeter method; this is even more remarkable as both methods utilized the same cross sections; and

ii) Excepting case 12, the ranges of mean monthly ecological flows provided by the hydrologic-hydraulic method are quite similar; in fact, for the others 11 cases the adoption of mean monthly ecological flows comprehended between 9 and $12 \%$ of the modulus can always be justified. 


\section{Conclusions and discussion}

A new method to define ecological flows based on hydrologic and hydraulic criteria was developed to Alentejo (South of Portugal) and it is briefly presented.

The hydrologic criteria account for the water scarcity and for the temporal irregularity of the natural hydrologic regime and the hydraulic criteria, for the geometry of the cross sections and of the river reaches. The data required by the application of the method to a given river reach are a series of mean daily flows and, as for the wet perimeter method, cross sections of that reach. In order to ensure that the special features of the flow regime are correctly considered, the previous series must be as long as possible (15 years or more). Also more than one cross section must be considered to attend the spatial variability of the geometry of the fluvial corridor.

The results achieved for 12 dams clearly show that the method is able to provide similar non-dimensional ecological flows despite the differences among watershed areas and mean annual flows depths. Mean monthly ecological flows from 9 to $12 \%$ of the modulus seem to be appropriate to the regional constraints. Based on each mean monthly ecological flow a monthly regime is established by applying eqn. (1).

Finally, it should be stressed that the validation of any ecological flow regime requires a continuous monitoring of the local ecosystems, which, for the time being, has not yet been done.

\section{References}

[1] Alves, M. H., 1993, Método de determinação do caudal ecológico, MSc Thesis. IST. Portugal.

[2] Alves, M. H., 2002, “Aproveitamentos hidráulicos, alterações dos regimes naturais e caudal ecológico" in Caudais ecológicos em Portugal, INAG, DSP, 2002, pp. 2.1-2.18. Portugal.

[3] Alves, M. H.; Bernardo, J. M., 2002, "Determinação de caudais ecológicos" in Caudais ecológicos em Portugal, INAG, DSP, 2002, pp. 3.1-3.27. Portugal.

[4] EDIA, Empresa de Desenvolvimento e Infra-Estruras do ALQUEVA, SA, www.edia.pt.

[5] Palau, T.; Alcazar, J., 1996, "The basic flow: an alternative approach to calculate minimum environmental instream flows", Procs 2 nd Int. Symp. on Habitat Hydraulic, Vol. A: 547-558. Canada.

[6] Palau, T.; Alcázar, C.; J. Roi, 1998, El Caudal Básico. Método para la gestión hidrobiológica de rios regulados, Informe Técnico para CEDEX. Spain.

[7] Portela, M. M. 2005, "Proposta de procedimento hidrológico hidráulico para definir caudais ecológicos em cursos de água do Sul de Portugal Continental", Recursos Hidricos, Vol. 26 (1), APRH. Portugal.

[8] Portela, M. M.; Quintela, A. C., 2005, "Regionalization of hydrologic information: establishment of flow series at ungauged watersheds", Water 
312 Sustainable Irrigation Management, Technologies and Policies II

Resources Management III (Carvoeiro, Portugal), Wessex Institute, WIT Press, ISBN 1-84564-007-1, pp. 11-20. Southampton, Boston.

[9] Portela, M. M.; Quintela, A. C., 2006, "Estimação em Portugal Continental de escoamentos e de capacidades úteis de albufeiras de regularização na ausência de informação". Recursos Hídricos, Vol. 27(2). APRH. Portugal.

[10] Portela, M. M., 2007, "A new method to define ecological flows in the South of Portugal", $2^{\text {nd }}$ International Congress. Energy and Environment Engineering and Management, IICIIEM2007. Badajoz, Spain.

[11] QUINTELA, A. (1967), Recursos de águas superficiais em Portugal Continental. PhD Thesis, IST. Portugal. 